\title{
EHMTI-0279. Deep brain stimulation for refractory chronic cluster headache
}

\author{
S Miller ${ }^{1 *}$, H Akram² ${ }^{2}$ S Lagrata', M Hariz², M Matharu', L Zrinzo ${ }^{2}$ \\ From 4th European Headache and Migraine Trust International Congress: EHMTIC 2014 \\ Copenhagen, Denmark. 18-21 September 2014
}

\section{Introduction}

Chronic cluster headache $(\mathrm{CCH})$ is an excruciating, unilateral headache with recurrent episodes of severe pain associated with ipsilateral autonomic features. $10-20 \%$ of patients are refractory to medical management. We present a prospective cohort of 19 patients with intractable $\mathrm{CCH}$ treated with posterior hypothalamic deep brain stimulation (DBS).

\section{Methods}

Patients with refractory $\mathrm{CCH}$ referred to multidisciplinary headache clinic at our centre underwent DBS. Clinical data was collected pre and post-treatment. Headache load (HAL) (defined as [severity (on the visual analogue score)] $x$ [duration] $x$ [frequency] of headaches over a 2 week period) was calculated before and after treatment. A treatment response was identified as a $30 \%$ or more reduction in HAL.

\section{Results}

19 patients $(M=15)$ with a median age of 48 years (33-67 years) underwent surgery. Median follow up time was 12 months (9-48 months). 17 patients had at least one year follow up. Five patients failed to respond to treatment but nine showed a reduction in HAL of more than $80 \%$. Within three months of surgery, the median change in HAL was $62 \%(0-100 \%)$ and at twelve months was $69 \%$ (0-100\%). Significant differences exist between HAL at baseline and at three $(\mathrm{p}=0.001)$ and twelve months $(p=0.06)$. There were no serious adverse events. One patient reported persistent diplopia, which was due to decompensation of a long-standing third nerve palsy.

\section{Conclusions}

Posterior Hypothalamic DBS appears a safe and effective treatment for $\mathrm{CCH}$ and should be considered for suitable patients who fail conventional treatment.

No conflict of interest.

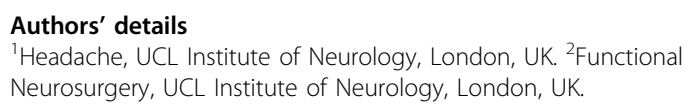

Published: 18 September 2014

doi:10.1186/1129-2377-15-S1-C44

Cite this article as: Miller et al.: EHMTI-0279. Deep brain stimulation for refractory chronic cluster headache. The Journal of Headache and Pain 2014 15(Suppl 1):C44
Submit your manuscript to a SpringerOpen ${ }^{\bullet}$ journal and benefit from:

- Convenient online submission

- Rigorous peer review

- Immediate publication on acceptance

- Open access: articles freely available online

- High visibility within the field

- Retaining the copyright to your article (c) 2014 Miller et al; licensee Springer. This is an Open Access article distributed under the terms of the Creative Commons Attribution License (http://creativecommons.org/licenses/by/2.0), which permits unrestricted use, distribution, and reproduction in any medium, provided the original work is properly cited. 